\title{
Trends in severe accident research in Europe: SARNET network from Euratom to NUGENIA
}

\author{
Jean-Pierre Van Dorsselaere ${ }^{1, *}$, François Brechignac ${ }^{1}$, Felice De Rosa ${ }^{2}$, Luis Enrique Herranz ${ }^{3}$, Ivo Kljenak ${ }^{4}$, \\ Alexei Miassoedov ${ }^{5}$, Sandro Paci $^{6}$, and Pascal Piluso ${ }^{7}$ \\ ${ }^{1}$ Institut de Radioprotection et de Sûreté Nucléaire (IRSN), BP3, 13115 Saint-Paul-lez-Durance, France \\ 2 Agenzia Nazionale per le nuove tecnologie, l'energia e lo sviluppo economico sostenibile (ENEA), Via Martiri di Monte Sole, 4 , \\ 40129 Bologna, Italy \\ ${ }^{3}$ Centro de Investigaciones Energéticas MedioAmbientales y Tecnológicas (CIEMAT), Avda. Complutense, 40, \\ 28040 Madrid, Spain \\ 4 Jozef Stefan Institute (JSI), Jamova cesta 39, SI-1000 Ljubljana, Slovenia \\ ${ }^{5}$ Karlsruhe Institute of Technology (KIT), Hermann-von-Helmholtz-Platz 1, 76344 Eggenstein-Leopoldshafen, Germany \\ ${ }^{6}$ University of Pisa, Dipartimento di Ingegneria Civile e Industriale (DICI), Largo Lucio Lazzarino 1, 56122 Pisa, Italy \\ ${ }^{7}$ Commissariat à l'Energie Atomique et aux Energies Alternatives (CEA), Cadarache, 13108 Saint-Paul-lez-Durance, France
}

Received: 19 June 2017 / Received in final form: 28 August 2017 / Accepted: 29 August 2017

\begin{abstract}
SARNET (Severe Accident Research Network) was set up under the aegis of the Framework Programmes of the European Commission from 2004 to 2013 and coordinated by IRSN to perform R\&D on severe accidents in water-cooled nuclear power plants. The network self-sustainability was achieved through integration mid-2013 in the NUGENIA European association devoted to R\&D on fission technology of Generation II and III. The SARNET activities continue in the technical area "Severe accidents" through technical workshops, ranking of R\&D priorities, improvements of severe accident codes, ERMSAR international conferences, and education and training courses. Six technical domains are addressed in this technical area: in-vessel corium/debris coolability, exvessel corium interactions and coolability, containment behaviour including hydrogen risk, source term released to the environment, impact of severe accidents on the environment and emergency management, and severe accident scenarios. The ranking of research priorities in the NUGENIA R\&D roadmap that was published in 2015 underlined the need to focus efforts in the next years on the improvement of prevention of severe accidents and on the mitigation of their consequences, as highlighted by the Fukushima Dai-ichi accidents. Several current projects on mitigation of severe accident consequences in Euratom or NUGENIA frame are shortly described in this paper.
\end{abstract}

\section{Introduction}

Despite accident prevention measures adopted in present nuclear power plants (NPP), some accidents, in circumstances of very low probability, may develop into severe accidents with core melting and plant damage and lead to dispersal of radioactive materials into the environment, thus constituting a hazard for the public health and for the environment. This risk was unfortunately underlined by the Fukushima Dai-ichi accidents in Japan in March 2011.

The SARNET network of excellence, coordinated by the Institut de Radioprotection et de Sûreté Nucléaire (IRSN, France), was launched in 2004 and co-funded until 2013 by the European Commission (EC) in the frame of the Euratom 6th and 7th Research and Development Framework Programmes (FP). The network self-sustainability was

\footnotetext{
* e-mail: jean-pierre.van-dorsselaere@irsn.fr
}

achieved through integration in mid-2013 in the NUGENIA European association devoted to R\&D on fission technology of Generation II and III NPPs.

The paper presents first the history of the two successive SARNET EC projects, and secondly the NUGENIA scope and activities. Section 4 summarizes the current activities on severe accidents in TA2/ SARNET. Section 5 describes shortly the diverse new projects that started in Euratom frame or are now under elaboration in H2020 or NUGENIA frame, most of them focusing on mitigation of severe accident consequences.

\section{SARNET history}

The SARNET's aim was to better coordinate the national efforts in Europe, optimising the use of the available expertise and of the experimental facilities, in order to resolve the remaining issues for enhancing the safety of existing and future NPPs. 
The 1st phase of SARNET, partially funded by EC within FP6, lasted from April 2004 until September 2008. The project, coordinated by IRSN, gathered 52 partners from 21 countries. The research work was divided into the following work-packages (WP) (those related to management, communication and education are omitted here):

- development and assessment of the ASTEC integral code

(jointly developed by IRSN and GRS);

- level 2 probabilistic safety assessment;

- early phase core degradation;

- late phase core degradation and vessel behaviour;

- ex-vessel corium recovery;

- hydrogen behaviour in containment;

- fast interactions in containment;

- fission product release and transport;

- aerosol behaviour impact on source term;

- containment chemistry impact on source term.

The 2nd phase of SARNET, within the EC FP7, lasted from April 2009 until March 2013. The project, again coordinated by IRSN, gathered 47 partners from 24 countries, including a few from North America and Asia. The overall work, involving about 250 researchers and 30 $\mathrm{PhD}$ students, represented an equivalence of 40 full-time persons per year. The research work was divided into a smaller number of WPs:

- ASTEC code development and assessment;

- corium and debris coolability;

- molten corium concrete interaction;

- containment;

- source term.

In the 1st phase, a group of experts ranked the research priorities, which underlined 20 technical issues to be addressed in priority from 2009 because of lack of knowledge and significance in the severe accident. This led to a much less fragmented organisation of the research work in the 2nd phase. This ranking was periodically updated to account for the results of recent research and, after 2011, for the impact of Fukushima Dai-ichi accidents.

For dissemination of knowledge among partners and beyond, 6 ERMSAR (European Review Meeting on Severe Accident Research) international conferences were organised, gathering between 100 and 150 participants, as well as 6 education and training courses, gathering between 40 and 100 students and young researchers. In addition a 750pages textbook on severe accident phenomenology was published [1]. Furthermore, a mobility programme aimed at training young researchers and students through a delegation at SARNET research teams was carrying out in order to enhance the exchanges and the dissemination of knowledge. This programme achieved 52 delegations with an average duration of about 3 months in 8 years.

Despite the initial scepticism, SARNET proved to be a success through the consolidation of the European severe accident research capacities and through the significant research achievements [2]. The main end-products have been a big database on many of those phenomena worth investigating and the knowledge capitalization in the ASTEC code through further development and extensive validation. The general response of research organisations showed that there is a strong willingness to cooperate so that only a minimal incentive is necessary. The large number of reports and papers with joint authorship testifies to this success: for instance in the network's 2nd phase, 101 papers in scientific journals and 262 presentations in international conferences were produced. After the formal end of the Euratom SARNET projects, contacts were still kept among participant organisations, which thus only needed a new formal framework to continue the collaborative research.

\section{NUGENIA}

NUGENIA ("NUclear GENeration II \& III Association"), an international non-profit association under the Belgian law, was officially set up on November 14, 2011, to provide a single framework for collaborative research and development concerning Generation II \& III nuclear systems (see www.nugenia.org). The association is composed by organisations from industry, research, safety and academia. At the end of 2016, it includes more than 100 members from many countries (including non-European countries Korea, Japan, USA and Canada).

NUGENIA stemmed from pre-existing R\&D networks of excellence, SARNET and NULIFE (the latter addressing plant life prediction) and a working group from the Sustainable Nuclear Energy Technology Platform (SNETP, see www.snetp.eu). There are 8 technical areas (TA) covering all industrial aspects of nuclear technology. The TA2, coordinated by IRSN, includes all activities on severe accidents that were previously performed in the Euratom SARNET projects (see Section 4).

In order to elaborate new research projects, the NUGENIA Open Innovation Platform (NOIP) was set up to share project ideas among members, consolidate them and finally build consortia. A label is then granted to the proposals with a high scientific quality and a consistent consortium of partners.

An important action has been the elaboration of the NUGENIA R\&D roadmap and its publication in 2015 [3]. This work showed that the main priority of $R \& D$ efforts in the next years must focus on the prevention of severe accidents and the mitigation of their consequences, as underlined by the Fukushima Dai-ichi accidents.

\section{Follow-up of SARNET activities in Nugenia}

Since mid-2013, NUGENIA TA2 "Severe Accidents" has encompassed the former SARNET network, with an extension of activities to the issues of "emergency and preparedness response" and "severe accident impact on the environment". The TA2/SARNET current activities are mainly:

- technical workshops;

- ranking of R\&D priorities;

- periodic ERMSAR conferences (organised every 2 years); - education and training courses (with the same frequency);

- and the elaboration of new $R \& D$ projects with the help of the NOIP tool. 
The impact of the activities towards young researchers or countries newly involved in nuclear energy is particularly relevant for dissemination of knowledge and gain of experience.

Six main domains are addressed in TA2/SARNET (coordinated by IRSN): in-vessel corium/debris coolability (led by KIT, Germany), ex-vessel corium interactions and coolability (led by CEA, France), containment behaviour including hydrogen risk (led by JSI, Slovenia) source term released to the environment (led by CIEMAT, Spain), severe accident scenarios (led by ENEA, Italy), impact of severe accidents on the environment and emergency management (led by IRSN). The activities on dissemination of knowledge are managed by the University of Pisa (Italy).

The 6th domain aims at creating an interface with the different European platforms of the radiation protection research community (MELODI, ALLIANCE, NERIS and EURADOS).

\section{Portfolio of R\&D projects on severe accidents}

As a consequence of the marked trend in NUGENIA R\&D roadmap on the mitigation of severe accident consequences, several new projects have started in the last years in Euratom or NUGENIA framework. They are shortly described below.

\subsection{Corium behaviour and coolability topics}

During the SARNET transition from Euratom to NUGENIA, five major projects were launched, in chronological order: SAFEST and ALISA (FP7), IVMR (H2020) and CORE-SOAR and QUESA (TA2/SARNET).

\subsubsection{SAFEST (Severe Accident Facilities for European Safety Targets)}

This FP7 project (that started mid-2014 for 4 years), led by KIT, is networking the European corium experimental laboratories with the objective to establish coordination in severe accident research facilities around Europe. This includes performing selected experiments using these key devices and producing research roadmaps for the next years. One of the main objectives is to address the issues related to accident analysis and corium behaviour. An example of such experiment is shown in Figure 1: in the SES facility at KTH (Sweden), a mixture of corium simulant materials was delivered under the surface of a water layer and led to spontaneous steam explosion.

The project is a valuable asset for the fulfilment of the severe accident $R \& D$ programmes that are being set up after Fukushima and the subsequent European stress tests, addressing both national and European objectives. Roadmaps on European severe accident experimental research for water reactors and for Generation IV technologies will be drafted. Improvements of the SAFEST facilities are included during the project: measurement of corium physical properties, improvement of instrumentation, consensus on scaling law rationales and cross comparison of material analyses.

\subsubsection{ALISA (Access to Large Infrastructures for Severe Accidents)}

This FP7 project (that started mid-2014 for 4 years), led by KIT, addresses the transnational access to large research infrastructures for optimal use of the R\&D resources in Europe and in China in the field of severe accident analysis for existing and future power plants. To optimise the use of the resources, the project provides access to experimental platforms in Europe to Chinese research institutes and access to Chinese experimental platforms for European research institutes.

Activities focus on large-scale experiments under prototypical conditions for severe accident issues in light water reactors (LWR) such as coolability of a degraded core, corium coolability in the reactor pressure vessel, possible melt dispersion to the reactor cavity, and hydrogen mixing and combustion in the containment. An example of such Chinese facility is shown in Figure 2: the COPRA facility in the Xi'an Jiaotong University is designed to study, at full scale in a 2D geometry, the natural convection heat transfer in corium pools within the vessel lower head at high Rayleigh numbers up to $10^{16}$.

\subsubsection{IVMR (In-Vessel Melt Retention severe accident management strategy for existing and future NPPs)}

The IVMR project [4], coordinated by IRSN, started mid2015 in the frame of H2020 EC work programme. It aims at providing new experimental data and a harmonized methodology for In-Vessel melt Retention (IVR). The IVR strategy for LWR intends to stabilize and isolate corium and fission products inside the reactor pressure vessel and in the primary circuit. This type of SAM strategy has already been incorporated in the severe accident management (SAM) guidance (SAMG) of several operating small-size LWRs below $500 \mathrm{MWe}$ (e.g. VVER440) and it is part of the SAMG strategies for some Gen III + PWRs of higher power such as AP1000 or APR1400. However, the demonstration of IVR feasibility for high power reactors requires using less conservative models as the safety margins are reduced. During the first year of the project, the work was mostly dedicated to an in-depth analysis of the methodology and to the computer code analysis. A synthesis of the methodology applied to demonstrate the efficiency of IVR strategy for VVER440 in Europe (Finland, Slovakia, Hungary and Czech Republic) was carried out. It has shown very consistent results, following quite comparable methodologies. The main weakness of the demonstration was identified in the evaluation of the heat flux that could be reached in transient situations, e.g. under the "3-layers" configuration of the corium pool in the lower plenum of the reactor vessel. Theoretical analyses have also started for various designs of reactors with a power between 900 and 1300 MWe. Large discrepancies of the results were observed, which were due to the use of very different models for the description of the molten pool: homogeneous, stratified with fixed configuration, and stratified with evolving configuration. The last type of model provides the highest heat fluxes (above $3 \mathrm{MW} / \mathrm{m}^{2}$ ) whereas the first type provides the lowest heat fluxes (around $500 \mathrm{~kW} / \mathrm{m}^{2}$ ). Obviously, there is an urgent 

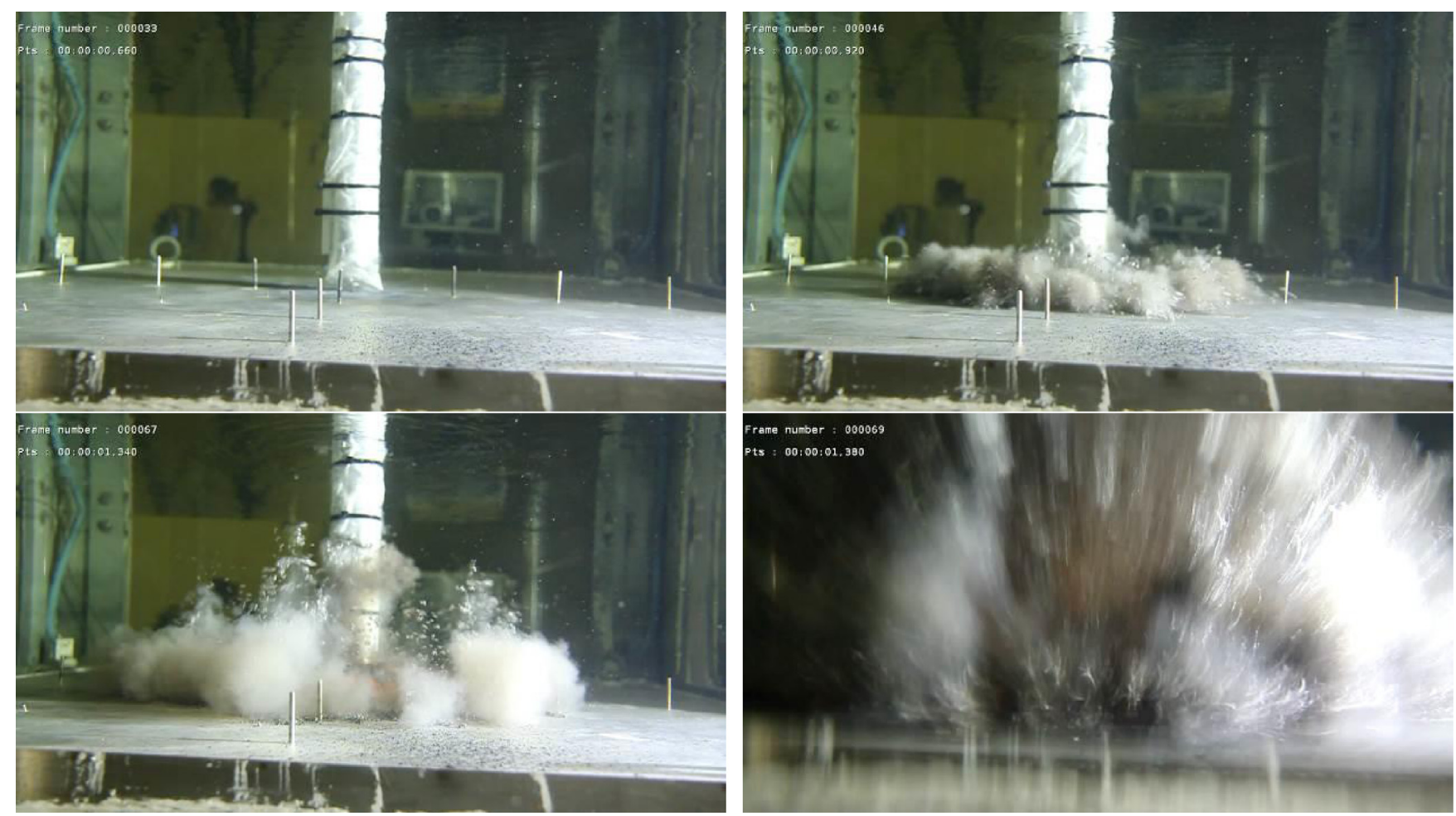

Fig. 1. Snapshots of the melt water interaction in SES-S1 test (@KTH, 2016).

need to reach a consensus about the best estimate practice to be used in the major codes for safety analyses, such as ASTEC, MELCOR, SOCRAT, MAAP and SCDAP/ RELAP. Despite the model discrepancies, and leaving aside the unrealistic case of a homogeneous pool, the average calculated heat fluxes in many cases are well above $1 \mathrm{MW} / \mathrm{m}^{2}$ which would threaten the integrity of the reactor vessel considerably and require a detailed mechanical analysis. Therefore, it is clear that the safety demonstration of IVR for high power reactors requires a more careful evaluation of the situations which can lead to formation of either a very thin top metal layer provoking a focusing effect or a significantly overheated metal, e.g. after oxide and metal layer inversion. The project will now focus on providing new experimental data (e.g. in facilities such as in NITI in Russian Federation: see Fig. 3) for situations of interest like the inversion of corium pool stratification and the kinetics of growth of the top metal layer. The project will also provide new data about the external vessel cooling from full-scale facilities: CERES (at MTA-EK in Hungary) for VVER-440 and a new facility built by UJV (Czech Republic) for VVER-1000. It will also include an activity on innovations dedicated to increase the efficiency of the IVR strategy such as delaying the corium arrival in the lower plenum, increasing the mass of molten steel or implementing measures for simultaneous in-vessel water injection.

\subsubsection{CoreSOAR (Core degradation State-of-the Art Report)}

This project, coordinated by IRSN, involves 11 European partners on the basis of their own resources in the TA2/ SARNET frame [5]. In 1991 the OECD Nuclear Energy
Agency Committee on Safety of Nuclear Installations (NEA/CSNI) published the first State-of-the-Art Report (SOAR) on In-Vessel Core Degradation [6] in water-cooled reactors, updated in 1995 under the EC FP3 [7]. These reports covered phenomena, experiments, material data, main modelling codes and their assessments, identification of modelling needs, and conclusions concerning needs for further research. This is relevant to such safety issues as invessel melt retention of the core, recovery of the core by water reflood, hydrogen generation and fission product release. In the following 20 years, there has been much progress in understanding, with major experimental programmes finished, such as the integral Phébus FP tests (IRSN), and others with many tests completed, e.g. QUENCH (KIT) on reflooding degraded rod bundles, and LIVE (KIT) on melt pool behaviour, and more generally in EC FP projects such as COLOSS and ENTHALPY. A similar situation exists regarding integral modelling codes such as MELCOR (USA) and ASTEC (Europe) that encapsulate current knowledge in a quantitative way. After the two EC SARNET successive projects, it is timely to take stock of the knowledge gained. The CoreSOAR project plans to update these SOARs over the two years to June 2018. At the roughly half-way stage of the project, data collection for the experimental side has now largely been completed, while the status of the main modelling codes is well under way. Following this review, research needs in the in-vessel core degradation area will be evaluated and main conclusions will be drawn. The main report will serve as a reference for ongoing research programmes in NUGENIA, in other H2020 research projects such as IVMR, and in CSNI future projects related to the Fukushima Dai-ichi accidents. The focus of the project to date is on the 


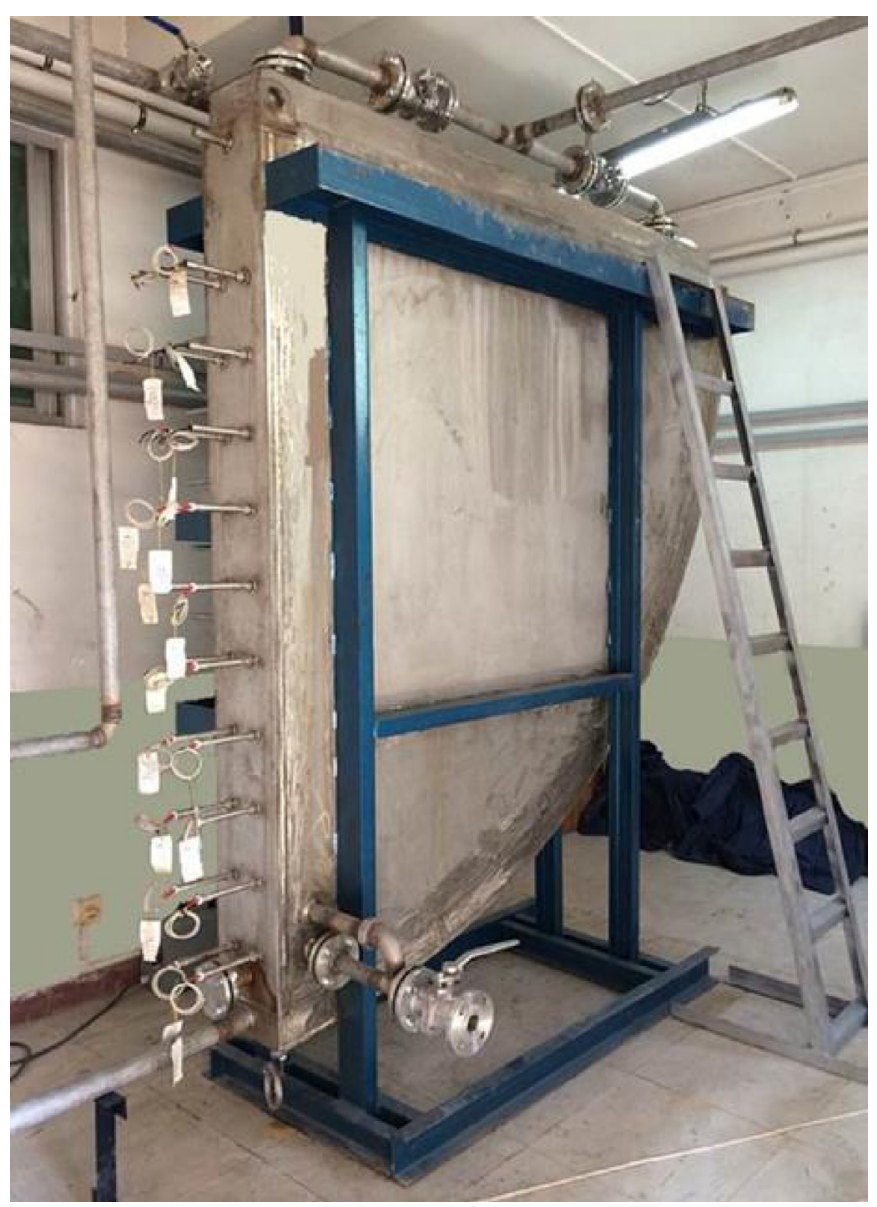

Fig. 2. Test vessel of the COPRA chinese facility in XJTU (@XJTU, 2016).

experiments on the in-vessel cooling of a degraded core, related to the important safety issue of IVR, and on fission product release, which would determine the source term to the environment if the vessel lower head were to fail and the containment were itself to fail or be vented.

\subsubsection{QUESA (QUEnch experiment with Steam and Air)}

This project, coordinated by GRS (Germany), involves 5 other partners (EDF and IRSN in France, LEI in Lithuania, PSI in Switzerland, plus IBRAE in Russian Federation) on the basis of their own resources in the TA2/ SARNET frame. It complements in a very efficient way the current SAFEST FP7 project by pre- and post-calculations of experiments done in the latter.

Extensive separate-effects tests have been performed recently for better understanding of the mechanisms of the oxidation of zirconium alloys in air atmosphere and the extraction of corresponding data mainly at IRSN and KIT. The accumulated data have demonstrated that cladding oxidation by air is a remarkably complicated phenomenon governed by numerous processes whose role can depend critically on the oxidizing conditions, the preceding oxidation history and the details of the cladding material specification. A number of air ingress bundle experiments on claddings have been performed under a range of configurations and oxidizing conditions, namely AIT-1, AIT-2, QUENCH-10, PARAMETER SF4 and QUENCH16. The results have shown a strong influence of nitrogen on the oxidation and degradation of zirconium-based claddings. These effects are most pronounced at intermediate temperatures $\left(800-1200^{\circ} \mathrm{C}\right)$ and longer times, i.e. slower transients. And, as it was shown in the QUENCH-16 test with pure air employed during the air ingress phase, these effects strongly increase the risk of a temperature runaway during the bundle reflooding. To complement the data for air-steam mixtures the QUESA project plans to perform a loss of coolant accident experiment in the QUENCH facility at KIT (Fig. 4) with pressurized fuel rod simulators, boil-off phase, air/ nitrogen ingress and final quenching. The project will focus on extending both phenomenological understanding and modelling of cladding oxidation under a mixture of air and steam. This QUESA experiment aims at studying and modelling more precisely the way the oxide layer is formed. It would be also an opportunity to investigate the influence of this kind of atmosphere on hydrogen production during the bundle reflooding.

The experiment will have the following objectives: - to better understand cladding oxidation under mixed atmosphere (air + steam), which is more representative of reactor applications;

- to see if nitriding can occur in such conditions: for representative flow rates, is there enough oxygen/steam or is nitrogen going to be consumed?

- to confirm that oxygen is the first gas to react with the cladding;

- to contribute to the evaluation of the impact of a porous oxide layer: does it enhance hydrogen production?

\subsection{Source term topics}

During the SARNET transition from Euratom to NUGENIA, three major projects have started on source term research, all closely related to some aspects highlighted during the Fukushima Dai-ichi accident. These three projects, in chronological order, are: PASSAM (FP7), FASTNET (H2020) and IPRESCA (TA2/SARNET).

\subsubsection{PASSAM (Passive and Active Systems on Severe Accident source term Mitigation)}

This project extended from 2013 to 2016 [8]. It was coordinated by IRSN and it involved 9 partners from 6 countries: IRSN, EDF and University of Lorraine (France); CIEMAT and CSIC (Spain); PSI (Switzerland); RSE (Italy); VTT (Finland) and AREVA GmbH (Germany). Mainly of an R\&D experimental nature, it aimed at studying phenomena that might have the potential for reducing radioactive releases to the environment in case of a severe accident. Its scope extended from the already existing mitigation devices (pool scrubbing systems; sand bed filters plus metallic prefilters) to innovative ones, which might help to achieve even larger source term attenuation (acoustic agglomeration systems; high pressure spray agglomeration systems; electric filtration systems; improved zeolite filtration 


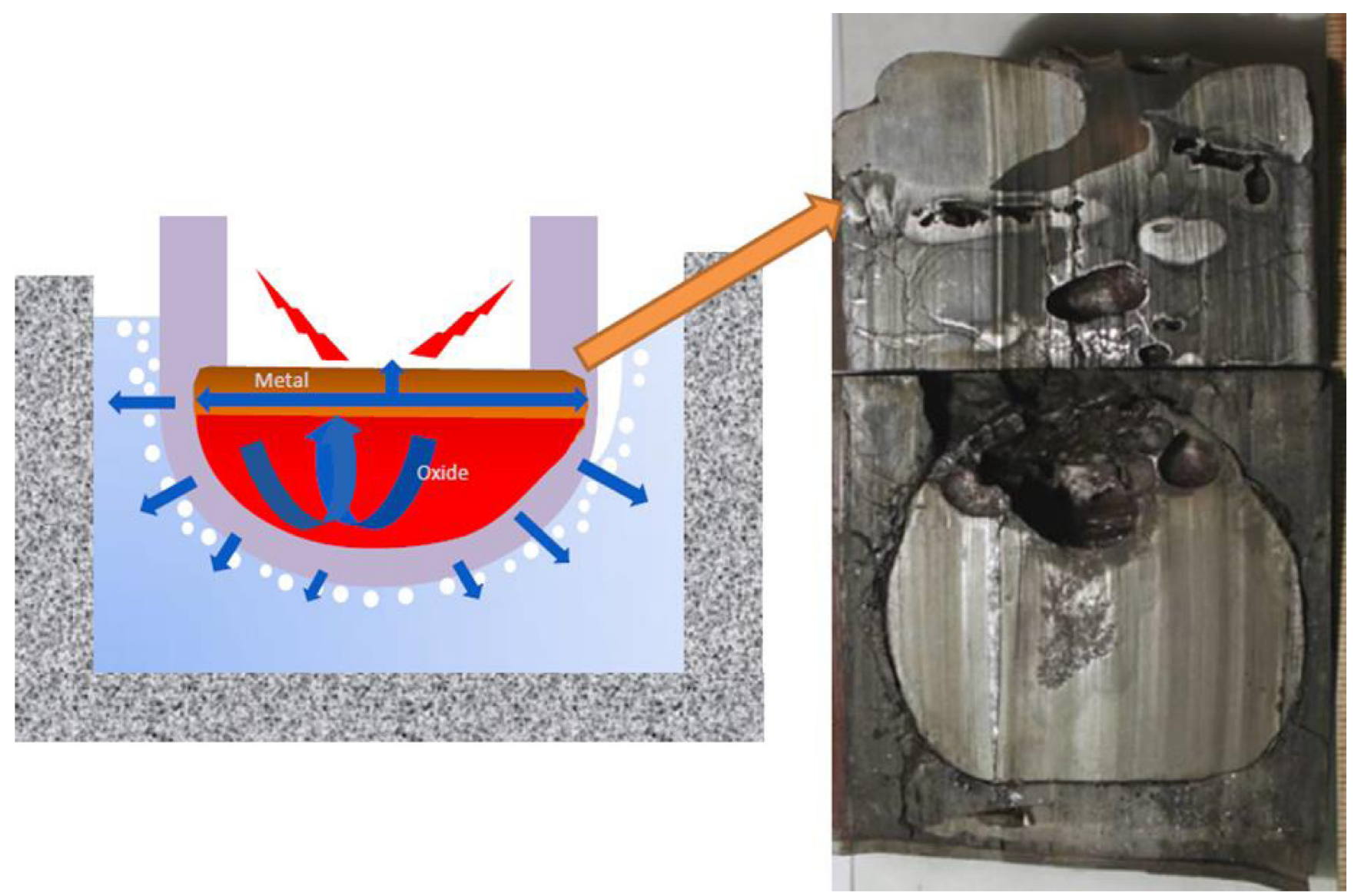

Fig. 3. CORDEB-2 experimental data (@NITI, 2015).

systems; combined filtration systems). Therefore, the project's major outcome has been an extensive and sound database to support the utilities and regulators in assessing the performance of the existing source term mitigation systems, evaluating potential improvements and developing SAM measures. In addition, simple models and/or correlations have been proposed for the investigated systems. Their implementation in severe accident analysis codes would result in an enhancement of their capability to model SAM measures and to develop improved guidelines.

Small and mid-size facilities have been used for these experimental campaigns: Figure 5 shows a few of them (mostly addressing pool scrubbing research).

Pool scrubbing represented the most studied domain. The in-pool gas hydrodynamics under the anticipated conditions has been shown to be significantly different from what is nowadays encapsulated in severe accident analysis codes, particularly at high velocities (i.e. jet injection regime and churn-turbulent flow). Additionally, it has been proved that maintaining a high $\mathrm{pH}$ in the scrubber solution in the long run is absolutely necessary for preventing a late iodine release. Sand bed filters (plus metallic pre-filters) have been demonstrated not to be efficient for gaseous molecular and/or organic iodides; on the other hand, caesium iodide aerosols trapped in the sand filter during a severe accident have been shown to be unstable and, hence, a potential delayed source term is possible. On the contrary, CsI particles trapped on the metallic pre-filter did not lead to any significant delayed release. As innovative processes, both acoustic agglomeration and high pressure spray systems were studied mainly in the aim of leading to bigger particles upstream of filtered containment venting systems, and so enhancing the filtration efficiency. An increase of the particle size by ultrasonic fields was experimentally observed and, more importantly, hard-to-filter particles (i.e. $0.1-0.3 \mu \mathrm{m}$ ) were drastically reduced in the particle size distribution. The increase in particle size by high pressure sprays could not be measured, but the system showed a better efficiency for reducing the airborne particle concentration than low pressure sprays. Experimental studies for trapping gaseous molecular and organic iodine using wet electrostatic precipitators (WESP) confirmed the importance of optimising the WESP design and the need of some pre-WESP steps (e.g. oxidation of $\mathrm{I}_{2}$ or $\mathrm{CH}_{3} \mathrm{I}$ into iodine oxide particles) for a good trapping efficiency.

Extensive testing of zeolites as trapper of molecular and organic iodine was performed and showed very good trapping efficiencies. In particular the so-called silver Faujasite-Y zeolites (with more than 15 wt.\% silver) displayed the highest ability for irreversible iodine trapping (Fig. 6). The trapping stability depends on the availability of silver sites to promote silver iodide formation. A very good stability of iodine trapped in silver zeolites under irradiation was observed, without any release. 


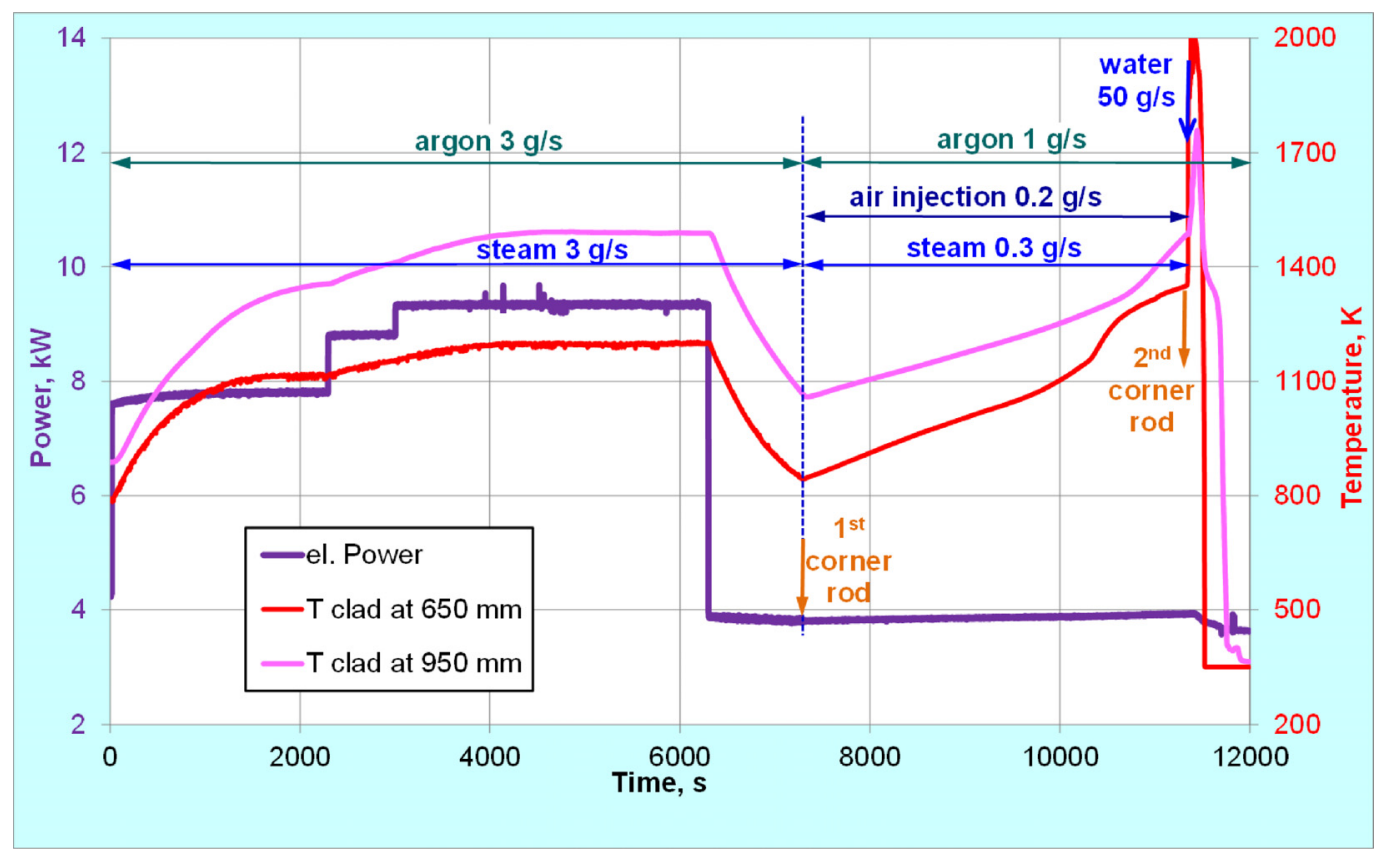

Fig. 4. Experimental protocol of the QUENCH test on air ingress planned in SAFEST (CKIT, 2017).

Finally, the combination of a wet scrubber followed by a zeolite filtration stage was extensively studied in representative severe accident conditions and showed the ability of this configuration to reach a significant retention for gaseous organic iodides.

\subsubsection{FASTNET (FAST Nuclear Emergency Tools)}

This project, coordinated by IRSN, started in October 2015 and involves 20 partners from 18 countries (including from North America, Canada and Russian Federation) and IAEA as third party [9]. When dealing with an emergency, two issues with fully different time requirements and operational objectives, and thus different methods and tools, have to be considered: the emergency preparedness and the emergency response. This project addresses both issues by combining the efforts of organisations active in these two areas to make a decisive step toward already identified deterministic reference methods and tools. In particular the capabilities of these methods and tools will be extended to tackle main categories of accident scenarios in operating or foreseen water-cooled NPPs in Europe, including a generic design of Spent Fuel Pools. A first task was the identification of these various scenarios, the proposition of a methodology for their description and the development of a database of scenarios. Building this database constitutes a first important step in the harmonization goal in this project. Promising probabilistic approaches based on Bayesian Belief Networks are currently developed to complement the operational deterministic methodologies and tools by diagnosing accidental situations. The development of the methodologies will be pursued by extending the existing deterministic ones to European reactors. Both approaches will be assessed against the above mentioned database of scenarios. Finally a comprehensive set of emergency exercises will be developed and calculated with tools by a large set of partners. A first series of exercises will address source term evaluations that will be compared to the reference source terms from the scenarios database. Then a second series of exercises will be proposed on the same scenarios but accounting for the main emergency objective of protecting the populations. Progress made by the methods and tools developed within this project will be assessed by comparing the results obtained in both series of exercises.

\subsubsection{IPRESCA (Integration of Pool scrubbing Research to Enhance Source-term CAlculations)}

This project, led by Becker Technologies (Germany), has been launched mid-2017 with more than 25 partners (from Europe and beyond) on the basis of their own resources in the TA2/SARNET frame [10]. It aims to integrate the international research in pool scrubbing phenomena by providing support in experimental research to broaden the current knowledge and database, and in analytical research. Experiments will be performed in facilities with range from lab scale $\left(\sim 1 \mathrm{~m}^{3}\right)$ to large scale $\left(\geq 60 \mathrm{~m}^{3}\right)$. As for the analytical work, specific pool scrubbing models applied in different system codes (e.g. ASTEC, COCOSYS and MELCOR) will be improved and validated through this improved database or even new models will be developed; for example computational fluid dynamics modelling is anticipated to investigate watergas hydrodynamics. The work packages are: critical (experimental/analytical) assessment of background, reference testing, innovation in pool scrubbing, and model enhancement and simulations. This includes assessment of data accuracy and experimental procedures. Particular importance will be given to instrumentation as enhanced modelling of pool scrubbing requires confidence in improved and reliable aerosol measurement techniques at first. 

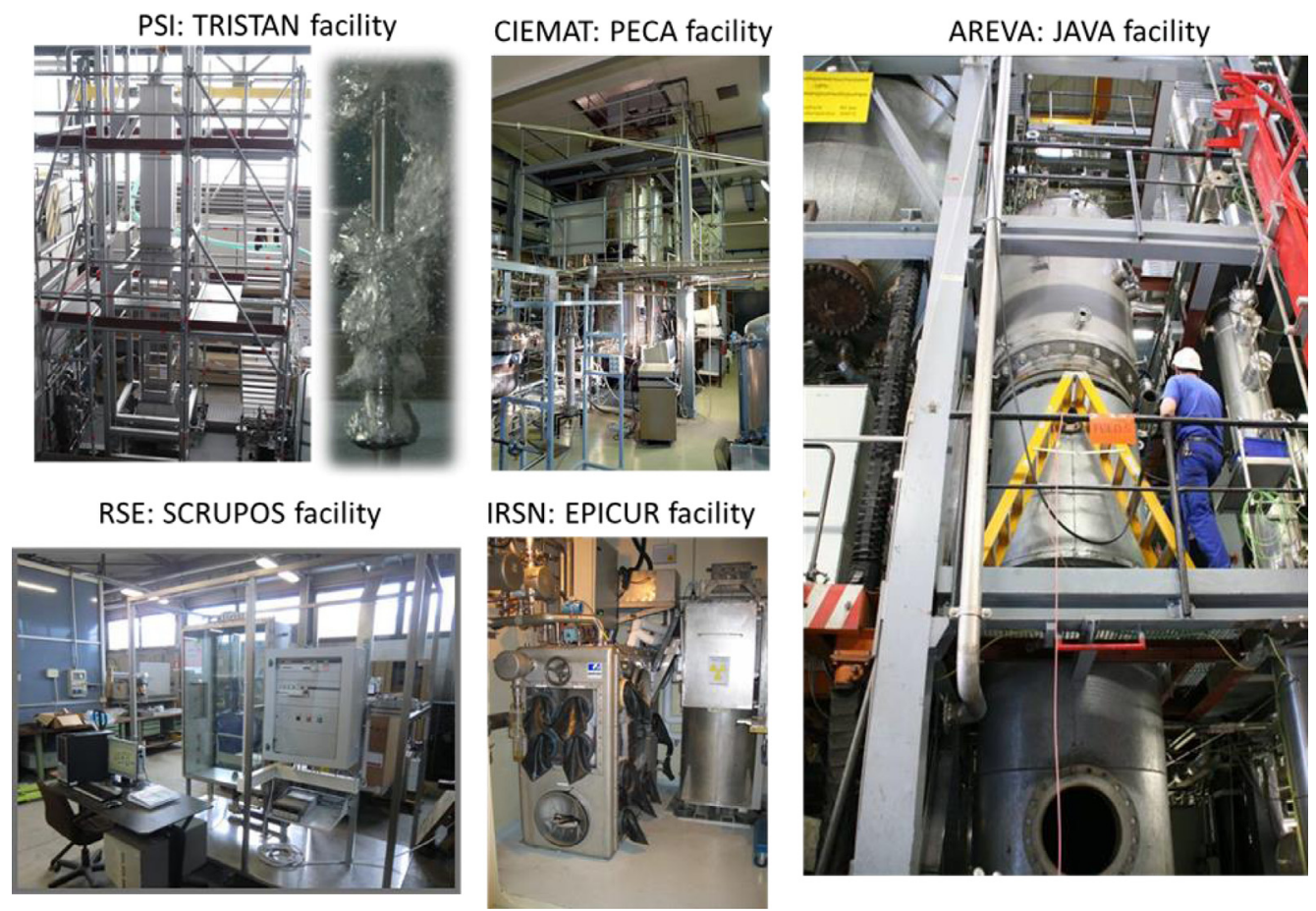

Fig. 5. Some selected PASSAM experimental facilities (CPASSAM, 2016).

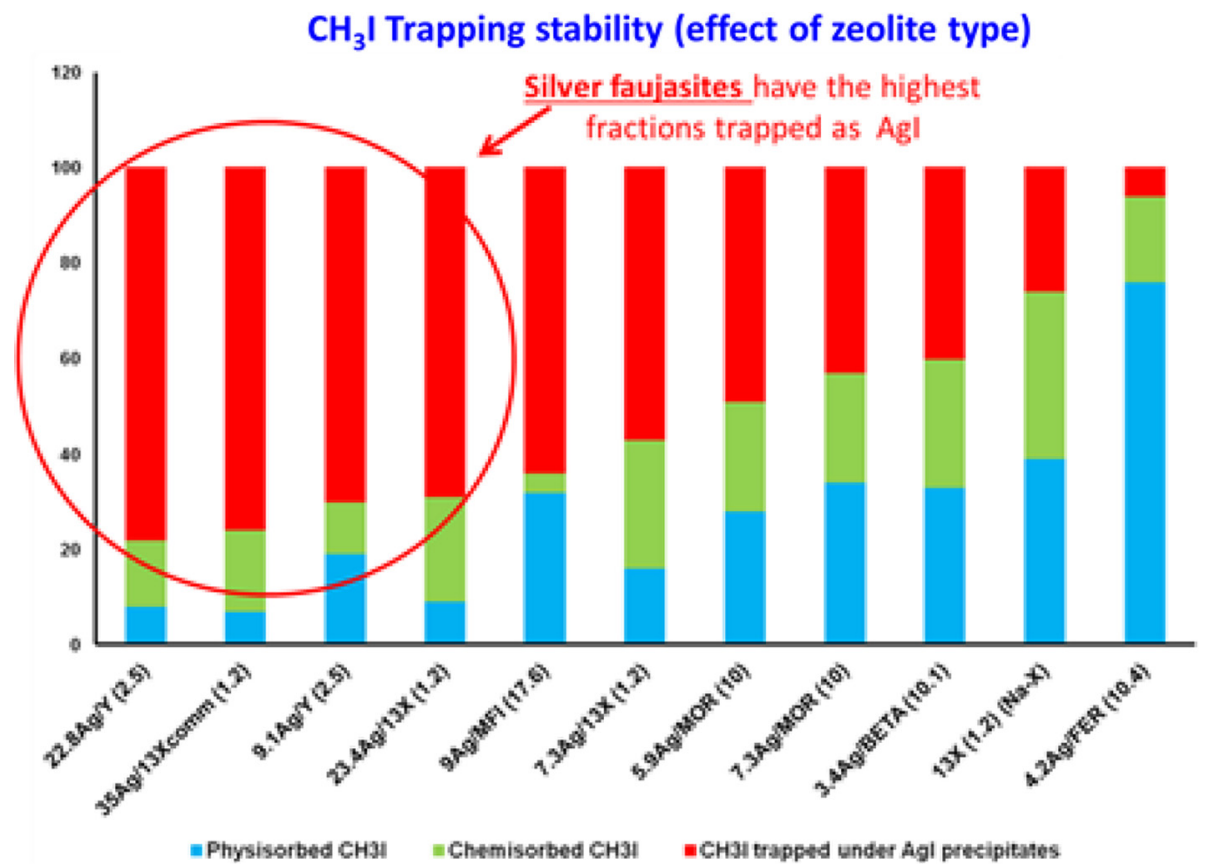

Fig. 6. Example of PASSAM results on zeolite retention capability (@University of Lorraine, 2016).

\subsection{Severe accident scenario simulation topics}

The CESAM (Code for European Severe Accident Management) FP7 project has been conducted from April 2013 until March 2017 in the aftermath of the Fukushima Dai-ichi accidents [11]. Nineteen international partners from Europe plus BARC in India and the European Joint Research Centre have been participating under the coordination of GRS
(Germany) and with a strong involvement of IRSN that were both the ASTEC code owners and developers (to date ASTEC is exculsively developed by IRSN).

The objectives were in priority an improved understanding of all relevant phenomena during the Fukushima Dai-ichi accidents and their importance for SAM measures as well as the improvement of the ASTEC computer code (Fig. 7) to simulate plant behaviour throughout accident 


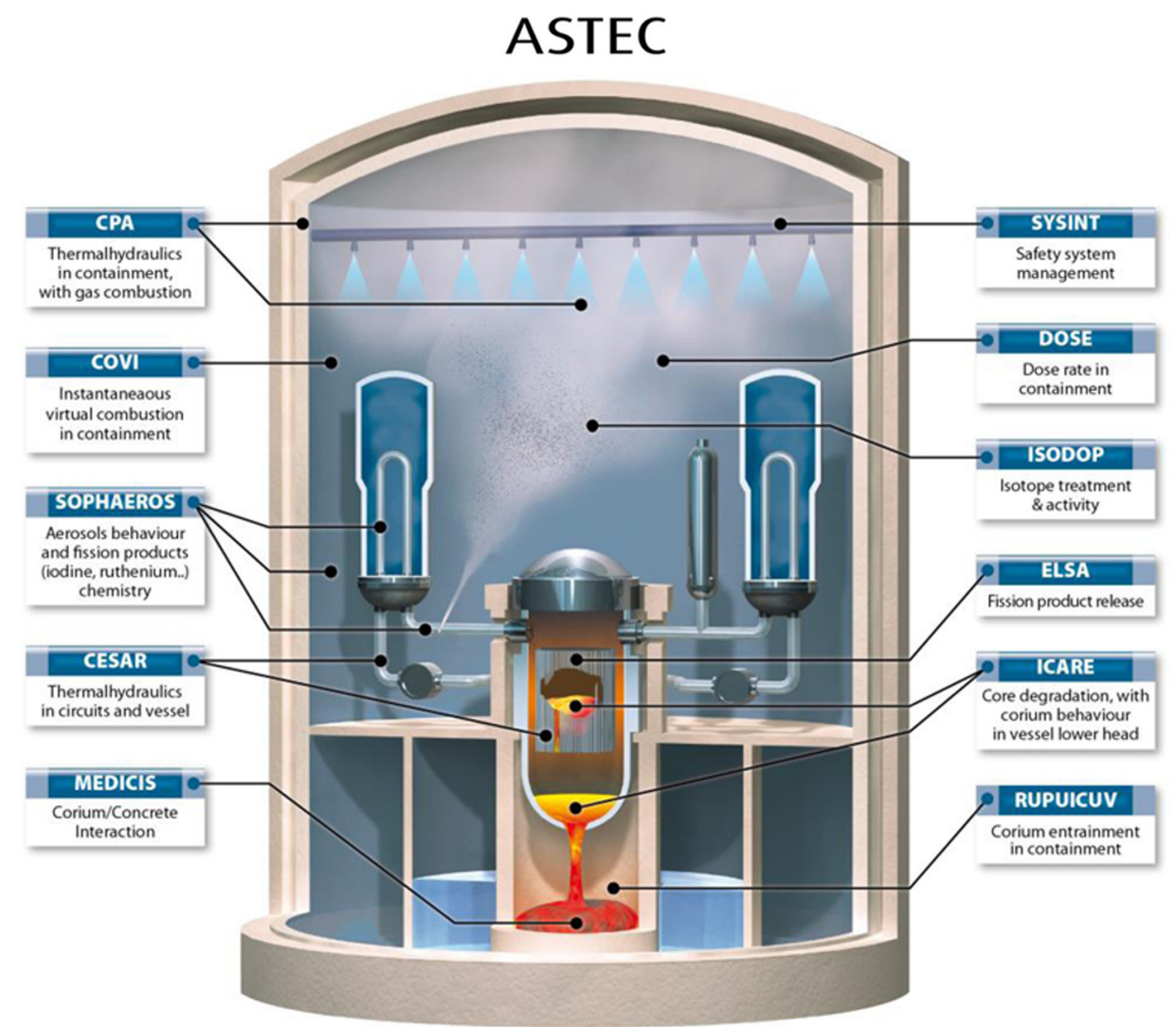

Fig. 7. ASTEC integral code for simulation of severe accidents (@IRSN, 2016).

H2 production

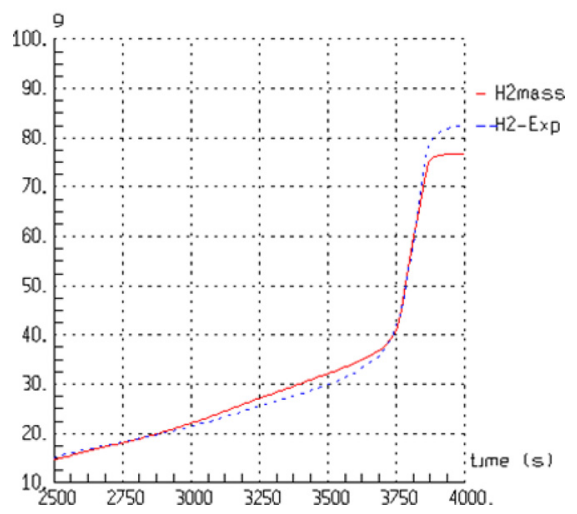

Fig. 8. Example of ASTEC validation vs. the QUENCH-08 reflooding experiment - hydrogen production in the bundle (@KIT, 2017).

sequences including SAM measures. One starting step was the analysis of current SAM measures implemented in European plants.

In order to achieve these goals, simulations of relevant experiments that allow a reliable validation of the ASTEC code against single and separate effect tests have been conducted. Topics in the CESAM project have been grouped into 9 different areas among which are re-flooding of degraded cores, pool scrubbing, hydrogen combustion, and spent fuel pools behaviour. Figure 8 shows the satisfactory comparison on the hydrogen production in the bundle in the QUENCH-08 reflooding experiment (performed at KIT) between ASTEC calculation results and measurements. This experiment addresses the bundle degradation followed by a quench phase in steam.

Furthermore, modelling improvements have been implemented in the current ASTEC V2.1 series for the estimation of source term consequences in the environment and the prediction of plant status in emergency centres. Finally, ASTEC reference input decks have been created for all reactor types operated in Europe today as well as for spent fuel pools. These input decks generically describe PWR, BWR, and VVER reactor types, without defining proprietary data of a specific plant and they account for the best recommendations from code developers. In addition, a generic input deck for a spent fuel pool was elaborated. These input decks can be used as basis by all (and especially new) ASTEC users in order to include their own plant details. Within CESAM, benchmark calculations have been performed with other codes (such as MELCOR, MAAP, ATHLET-CD and COCOSYS) with a focus on the effectiveness of currently implemented SAM measures based on these generic input decks.

\section{Conclusion}

There are many activities in the TA2/SARNET framework with several ongoing research projects on severe accidents or others that are about to start soon, either in the H2020 frame or as NUGENIA in-kind projects. 
In April 2017 the 8th ERMSAR conference of the network, hosted by NCBJ in Warsaw (Poland) (see www.ermsar2017. ncbj.gov.pl), was a big success with 170 participants from 25 countries: it was the opportunity to share the recent progress of research among European organisations but also many organisations coming from North America, Japan, China, India, Russian Federation and Ukraine.

In late 2017 an update of the ranking of $R \& D$ priorities on severe accidents will be performed in the frame of the NUGENIA roadmap periodic update, in order to account for recent progress of knowledge since the latest ranking in 2013.

The major challenge that TA2/SARNET faces in the near future is the possible restriction of $R \& D$ funding in the domain of severe accidents. By contrast, the strengthening of links with other institutions, like OECD/NEA/CSNI, to extend the networking could be a positive factor to improve the effectiveness of severe accident research in Europe.

The authors of the present paper wish to acknowledge the coordinators of the above mentioned projects or proposals, namely F. Fichot (IVMR), T. Haste (CoreSOAR), T. Albiol (PASSAM), I. Devol-Brown (FASTNET), E. Beuzet from EDF and T. Hollands from GRS (QUESA), S. Gupta (IPRESCA) from Becker Technologies, and H. Nowack (CESAM) from GRS.

\section{References}

1. B.R. Sehgal et al., Nuclear Safety in Light Water Reactors, Severe Accident Phenomenology, 1st edn. (Elsevier, 2012)

2. J.P. Van Dorsselaere, A. Auvinen, D. Beraha, P. Chatelard, L. E. Herranz, C. Journeau, W. Klein-Hessling, I. Kljenak, A. Miassoedov, S. Paci, R. Zeyen, Nucl. Eng. Des. 291, 19 (2015)
3. NUGENIA Global Vision, version April 2015, revision 1.1, ISBN 978-2-919313-07-5

4. F. Fichot, L. Carénini, J.M. Bonnet, Main physical questions raised by In-Vessel Melt Retention, in Proceedings of the International Workshop on In-Vessel Retention, Aix-enProvence, France, 2016

5. T. Haste, CoreSOAR: core degradation state-of the art update, in Proceedings of the NUGENIA Forum, Marseille, France, April 5-7, 2016

6. S.R. Kinnersly et al., In-vessel core degradation in LWR severe accidents: a state of the art report to CSNI, Report OECD/NEA/CSNI/R(91)12, 1991

7. T. Haste, B. Adroguer, U. Brockmeier, P. Hofmann, K. Müller, M. Pezzili, In-vessel core degradation in LWR severe accidents, Report EUR16695EN, 1996

8. T. Albiol, L.E. Herranz, E. Riera, C. Dalibart, T. Lind, A. Del Corno, T. Kärkel, N. Losch, B. Azambre, The European PASSAM project: R\&D outcomes towards enhanced severe accident source term mitigation, in Proceedings of the International Congress of Advanced Nuclear Power Plants (ICAPP-2017), Fukui and Kyoto, Japan, April 24-28, 2017

9. FASTNET website, https://www.fastnet-h2020.eu

10. S. Gupta, L.E. Herranz, J.P. Van Dorsselaere, Integration of pool scrubbing research to Enhance Source Term calculations, in Proceedings of the European Review Meeting of Severe Accident Research (ERMSAR 2017), Warsaw, Poland, May 16-18, 2017

11. J.P. Van Dorsselaere, P. Chatelard, K. Chevalier-Jabet, H. Nowack, L.E. Herranz, G. Pascal, V.H. Sanchez-Espinoza, ASTEC code development, validation and applications for severe accident management within the CESAM European project, in Proceedings of the International Congress on Advances in Nuclear Power Plants (ICAPP-2015), Nice, France, May 3-6, 2015

Cite this article as: Jean-Pierre Van Dorsselaere, François Brechignac, Felice De Rosa, Luis Enrique Herranz, Ivo Kljenak, Alexei Miassoedov, Sandro Paci, Pascal Piluso, Trends in severe accident research in Europe: SARNET network from Euratom to NUGENIA, EPJ Nuclear Sci. Technol. 3, 28 (2017) 